\title{
Programa de Pós-Graduação em Antropologia Social da Universidade Federal de São Carlos (PPGAS-UFSCar)
}

O Programa de Pós-Graduação em Antropologia Social da Universidade Federal de São Carlos (PPGAS-UFSCar) foi recomendado pela CAPES em outubro de 2006 e está em atividade desde o primeiro semestre de 2007 (curso de mestrado, com doutorado iniciado em 2009). Procura atender tanto à demanda por uma formação discente e profissionalizante mais específica e adequada às linhas de pesquisa desenvolvidas, quanto fortalecer a crescente expansão das atividades de ensino, pesquisa e extensão dos docentes da área em um projeto acadêmico que lhe seja próprio e reúna as condiçóes acadêmicas e institucionais para a sua maior consolidação e autonomia. De acordo com a formação e a especialização do corpo docente, seis linhas de pesquisa se desdobram na área de concentração do PPGAS. São elas: Antropologia da Saúde, do Esporte e Corporalidade; Antropologia da Política, da Violência e do Estado; Deslocamentos, Memória e Territorialidades; Antropologia: Questôes Interdisciplinares, Teóricas e Metodológicas; Etnologia: Conhecimentos Indígenas e Interculturalidade e Antropologia Urbana.

\section{Docentes permanentes:}

Clarice Cohn

Doutora, Antropologia, USP, 2006

Etnologia Indígena; Antropologia da Criança; Antropologia da Saúde; Educação Escolar Indígena

Débora Cristina Morato Pinto

Doutora, Filosofia, USP, 2000

Epistemologia; Subjetividade

Geraldo Luciano Andrello

Doutor, Antropologia, Unicamp, 2004

Etnologia e História Indígenas; Política e Ritual; Mito e Cosmologia

Igor José de Renó Machado

Doutor, Antropologia, Unicamp, 2003

Migraçôes Internacionais; Natureza e Cultura; Infância

Jorge Luiz Mattar Villela

Doutor, Antropologia, Museu Nacional/UFRJ, 2003

Violência; Política; Tempo e Espaço

cadernos de campo, São Paulo, n. 19, p. 1-384, 2010 
$368 \mid$ PPGAS-UFSCAR

Luiz Henrique de Toledo

Doutor, Antropologia, USP, 2000

Esporte; Técnicas Corporais; Festas; Antropologia Urbana

Marcos P. D. Lanna

Doutor, Antropologia, University of Chicago, 1991

Teoria Antropológica; Casa e Parentesco; Dádiva e Mercado

Marina Denise Cardoso

Doutora, Antropologia, University of London, 1994

Antropologia da Saúde; Etnologia Indígena; Práticas Terapêuticas

Piero de Camargo Leirner

Doutor, Antropologia, USP, 2001

Antropologia da Guerra; Estado; Hierarquia e Individualismo

\section{Docentes colaboradores:}

Aristóteles Barcelos Neto

Doutor, Antropologia, USP, 2004

Etnologia Indígena; Antropologia da Arte; Ritual e Cosmologia

University of East Anglia, ANGLIA/ Inglaterra

Edmundo Antonio Peggion

Doutor, Antropologia, USP, 2005

Etnologia Indígena; Dualismo; Parentesco e Organização Social

UNESP/Araraquara

Renato Sztutman

Doutor, Antropologia, USP, 2005

Etnologia e História Indígena; Ritual, Política e Xamanismo Indígena

USP/São Paulo 